\title{
2D Based Puppet Character Introduction Game Using Construct 2
}

\section{Game Pengenalan Tokoh Wayang Berbasis 2D Menggunakan Construct 2}

\author{
Siska Dyah Pertiwi ${ }^{1 *}$, Cindy Taurusta ${ }^{2}$, Mohammad Suryawinata ${ }^{3}$, Yulian Findawati ${ }^{4}$ \\ \{ siskadyah0505@gmail.com¹, cindytaurusta@umsida.ac.id², suryawinata@umsida.ac.id ${ }^{3}$, \\ yulianfindawati@umsida.ac.id $\left.{ }^{4}\right\}$
}

Program Studi Informatika, Fakultas Sains dan Teknologi, Universitas Muhammadiyah Sidoarjo

\begin{abstract}
Indonesia has a very diverse culture. As in Java, many people still use Javanese language and have their own special art namely wayang. Many people now do not know about who the puppet characters, education has an important role to develop the potential and character of children. Fun learning media is needed by students. This research uses library study methods and interview to elementary school teachers. This game covers Javanese language subjects in grade 3-5, especially discussing material about puppet characters. Materials used under the 2013 Curriculum. This game has 3 level stages. In each game, players must collect 3 puppet after which the player will get the final score and also information about the puppets material adjusted to the level of Class. Also conducted 4 test with an average percentage of $98 \%$ and get a good response.
\end{abstract}

Keywords - Game; Javanese language; Puppet Character

Abstrak. Indonesia memiliki budaya yang sangat beragam. Seperti di pulau Jawa banyak orang masih menggunakan bahasa jawa dan memiliki kesenian khasnya yaitu wayang. Banyak orang sekarang yang kurang mengetahui tentang siapa saja tokoh-tokoh wayang, pendidikan mempunyai peran penting untuk mengembangkan potensi dan karakter anak. Media pembelajaran yang menyenangkan sangat dibutuhkan oleh pelajar. Penelitian ini menggunakan metode studi pustaka dan wawancara kepada guru SD. Game ini mencakup mata pelajaran bahasa jawa kelas 3-5 khususnya membahas materi tentang tokoh wayang. Materi yang digunakan berdasarkan Kurikulum 2013. Game ini memiliki 3 tahapan level. Disetiap permainan, pemain diminta untuk mengumpulkan 3 wayang setelah itu pemain akan mendapatkan poin akhir dan juga informasi mengenai materi wayang disesuaikan dengan tingkatan Kelas. Dilakukan juga 4 pengujian dengan rata-rata presentase mencapai $98 \%$ dan mendapatkan respon yang baik.

Kata Kunci-Game; Bahasa Jawa; Tokoh Wayang

\section{Pendahuluan}

Negeri Indonesia adalah negeri maritim yang memiliki banyak sekali pulau-pulau besar yang dimana terdapat juga beragam budaya, suku, adat istiadat, agama, bahasa dan juga bermacam-macam kesenian tradisional. Keseluruh kebudayaan lokal yang ada disetiap daerah di Indonesia ialah Kebudayan Indonesia [5]. Disetiap daerah pasti memiliki ciri khas bahasa dan budaya yang mereka anut dan gemari masing-masing. Seperti di pulau Jawa banyak orang yang menggunakan bahasa jawa dan juga ada kesenian wayang masih terus dilestarikan sampai sekarang. Semenjak \pm 1500 tahun yang lalu kesenian wayang merupakan salah satu macam kebudayaan Jawa yang sudah terdapat serta diketahui oleh masyarakat [1]. Kesenian wayang sangatlah beragam dan memiliki cerita sejarah yang berbeda-beda pula. Agar kesenian wayang tidak punah maka kita harus menjaga serta melestarikan kesenian wayang tersebut.

Meski begitu jika kita ingin menengok lebih dalam, ternyata keberadaan wayang dalam kehiduapan masyarakat jawa masih sangat kental [9]. Sebagai upaya pelestarian kesenian wayang, dunia pendidikan bahkan sudah memasukkannya kedalam mata pelajaran sejak di Sekolah Dasar. Sekolah dasar berada dalam naungan Kementrian Pendidikan dan Kebudayaan (Kemendikbud) sedangkan Madrasah Ibtidaiyah oleh Kementrian Agama [10]. Dalam mata pelajaran bahasa jawa, siswa diajarkan mengenai tata krama, unggah-ungguh basa serta cerita pewayangan. Dalam pewayangan memiliki banyak sekali tokoh-tokoh wayang dan pastinya mempunyai cerita masing-masing. Penyebab minat siswa yang rendah dalam mengenal tokoh wayang adalah fasilitas pembelajaran yang kurang memadai [6]. Dari permasalahan tersebut muncul ide membuat media pembelajaran Bahasa Jawa yang interaktif untuk dapat mengenal tokoh-tokoh wayang.

Dalam mendukung pengajaran dan pembelajaran yang menggunakan teknologi multimedia interaktif, game pengenalan ini dirancang untuk pengembangan pendidikan [8]. Dalam mengembangkan atau memanfaatkan teknologi game saat ini, maka media pembelajaran interaktif melalui sebuah game yang menyampaikan informasi berupa gambar dan pemain dituntut untuk menyelesaikan tantangan yang diberikan. Game ini membahas mengenai materi wayang yang ada di mata pelajaran bahasa jawa. Game ini akan disajikan dengan beragam bentuk animasi dan siswa diharapkan dapat menyelesaikan rintangan yang diberikan. Lalu disetiap akhir level akan diberikan reward score dan juga akan menampilkan info tentang wayang. Tujuan adanya pengembangan game pengenalan wayang ini yaitu untuk membantu meningkatkan kemampuan dan juga perkembangan anak dalam belajar [7]. 
Semenjak \pm 1500 tahun yang lalu kesenian wayang merupakan salah satu macam kebudayaan Jawa yang sudah terdapat serta diketahui oleh masyarakat [1]. Wayang telah melekat dalam budaya bangsa Indonesia, khususnya masyarakat Jawa. Dalam pembelajaran di SD juga memasukkan materi mengenai pewayangan yang mulai di pelajari di kelas 3-5. Berikut Kompetensi Dasar yang mempelajari mengenai wayang yang dimuat dalam Muatan Lokal Kurikulum 2013 Mata Pelajaran Bahasa Jawa :

1. Kelas 3 SD : Mengenal nama dan gambar tokoh Pandawa yaitu Yudhistira, Bima/Werkudara, Arjuna/Janaka, Nakula \& Sadewa.

2. Kelas 4 SD : Memahami cerita wayang tentang tokoh Yudhistira/Puntadewa.

3. Kelas 5 SD : Memahami teks cerita wayang Pandawa "Karna Madeg Senapati".

Sebuah sistem dimana pemain terlibat konflik buatan itu dinamakan sebuah game atau permainan.. Game adalah suatu sistem dimana terdiri dari satu pemain atau lebih yang dapat mengambil keputusan melalui kendali suatu objek untuk tujuan tertentu [4]. Jenis-jenis genre dalam sebuah game seperti Action, FPS (Fisrt Person Shooter), Fighting Game, RTS (Real Time Strategy), RPG (Role Playing Game), Education, Adventure, Simulasi, Sport, Racing dan Puzzle. Jenis genre game yang pemain gunakan dalam pembuatan game pengenalan tokoh wayang ini adalah genre Adventure.Game juga dikelompokkan dalam beberapa dimensi seperti game 2D, 2.5D dan juga 3D.

Construct 2 ialah software game yang dikembangkan oleh Scirra yang berbasis HTML5 yang merupakan platform khusus uunutk membuat game 2D. Kelebihan dari Construct 2 ini sudah mencakup Event serta Action dalam melakukan suatu perintah sehingga tidak perlu lagi menggunakan bahasa pemrograman khusus. Adapun fitur dari Construct 2 [3] yaitu : Quick and Easy, Flexible Behaviors, Powerfull Event System, Instant Preview, Multiplatfrom Export, Stunning Visual Effects dan Easy Extensibility.

\section{METODE}

Penelitian di lakukan di Laboratorium Multimedia Universitas Muhammadiyah Sidoarjo sebagai tempat belajar serta untuk penyusunan laporan dilakukan di kediaman penulis. Waktu dilakukan penelitian ini dimulai dari tanggal 12 Oktober 2020. Alat dan juga bahan penunjang yang penulis gunakan dalam penelitian ini adalah sebagai berikut : Alat yang digunakan untuk memabantu proses penelitian dan penyusunan game yaitu Laptop Toshiba Satellite L8301001 Core i3 2377M 1.5GHz dan Construct 2. Bahan Penelitian yang digunakan dalam penelitian ini adalah Buku LKS Bahasa Jawa Kurikulum 2013 dan Video-video tutorial pembuatan game menggunakan Construct 2 yang diperoleh dari Youtube.

\section{A. Metode yang digunakan}

1. Metode Studi Pustaka yaitu metode yang digunakan untuk mengumpulkan segala data dan informasi yang relevan yang berkaitan dengan topik penelitian. Informasi serta data yang diperoleh berasal dari buku dan hasil bertanya dengan teman dari Jurusan PGSD yang mengajar les privat.

2. Metode Wawancara ini dilakukan kepada guru dari SD Al Huda Wadungsari pada hari Jumat, 13 November 2020 untuk memastikan apakah materi wayang sudah sesuai dengan materi yang ada di mata pelajaran Bahasa Jawa di Sekolah Dasar.

\section{B. Perancangan sistem}

Berikut ini adalah aturan dalam permainan game pengenalan wayang :

1. Dalam permainan hanya ada satu player.

2. Lalu player memilih menu kategori kelas sesuai tingkat kelas masing-masing.

3. Player menyelesaikan rintangan untuk mendapatkan reward skor item berupa wayang dan koin.

4. Setiap kelas / level selesai dan mendapat reward maka player juga akan mendapatkan info materi mengenai wayang sesuai dengan tingkatan kelas masing-masing.

5. Pemain dianggap lulus dengan mengumpulkan 3 item wayang dan jika kurang dari 3 maka akan kalah.

\section{Finite state machine (fsm)}

Berikut adalah desain perancangan Finite State Machine (FSM) pada game pengenalan tokoh wayang : 


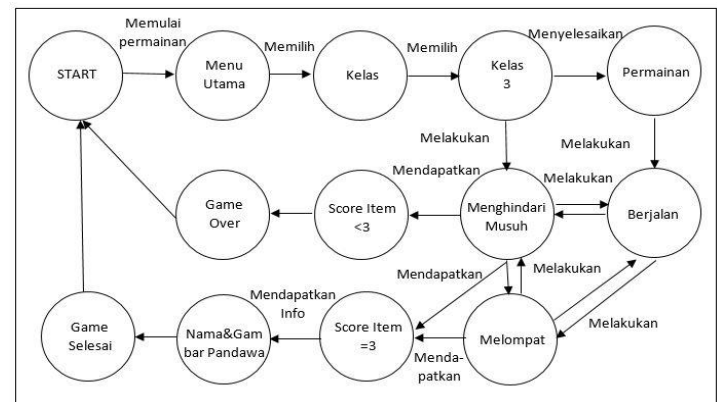

Gambar 1. FSM Scene Kelas 3

Pada gambar diatas menjelaskan Finite State Machine (FSM) Scene untuk menjalankan permainan di kategori kelas 3 dan jika menang maka pemain akan mendapatkan reward berupa score item dan juga info mengenai nama dan gambar wayang Pandawa.

Fsm scene kelas 4

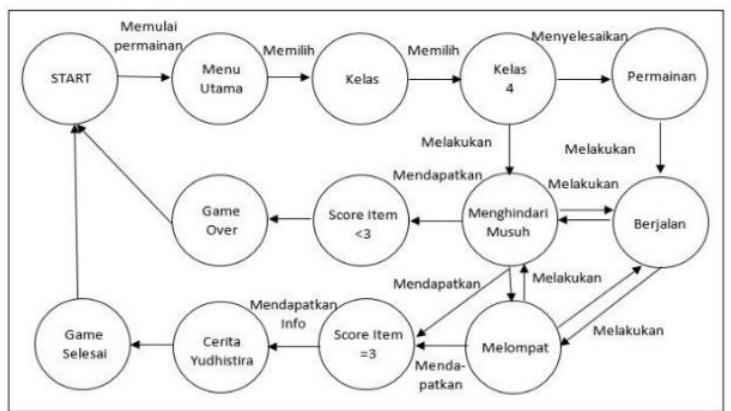

Gambar 2. FSM Scene Kelas 4

Pada gambar diatas menjelaskan Finite State Machine (FSM) Scene untuk menjalankan permainan di kategori kelas 4 dan jika menang maka pemain akan mendapatkan reward berupa score item dan juga info mengenai cerita tokoh Yudhistira.

Fsm scene kelas 5

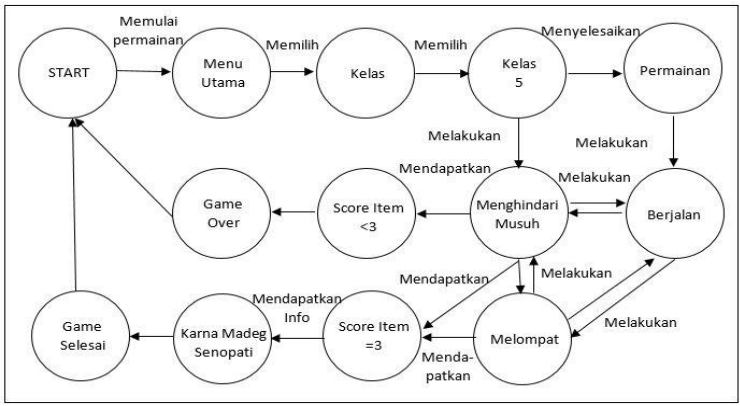

Gambar 3. FSM Scene Kelas 5

Pada gambar diatas menjelaskan Finite State Machine (FSM) Scene untuk menjalankan permainan di kategori kelas 5 dan jika menang maka pemain akan mendapatkan reward berupa score item dan juga info mengenai cerita Karna Madeg Senapati.

\section{Desain karakter}

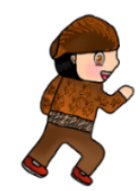

Gambar 4. Karakter Player Game Pengenalan Tokoh Wayang 
Procedia of Engineering and Life Science Vol. 1. No. 2 Juni 2021

Seminar Nasional \& Call Paper Fakultas Sains dan Teknologi (SENASAINS 2nd)

Universitas Muhammadiyah Sidoarjo

Karakter di atas adalah karakter yang menggambarkan seseorang yang menggunakan pakaian batik dan juga mengenakan blangkon yang merupakan pakain ciri khas orang Jawa.

\section{HaSil dan Pembahasan}

Dalam penelitian ini menghasilkan sebuah game pengenalan tokoh wayang yang dimana game adventure ini dapat menjadi permainan yang menyenangkan dan juga dapat memberikan informasi materi mengenai wayang dalam mata pelajaran Bahasa Jawa Sekolah Dasar yang bisa dijalankan dan diaplikasikan di Android. Dalam tahap pengimplementasian sebuah game, juga harus memperhatikan fungsi dan tujuannya apakah sudah mencapai tujuan yang ditentukan dalam pembuatan game pengenalan tokoh wayang menggunakan Construct 2 ini.

1. Tampilan Menu Utama

2. Tampilan Menu Kelas/Level

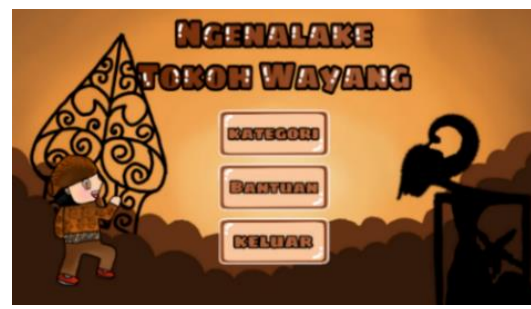

Gambar 5. Tampilan Menu Utama

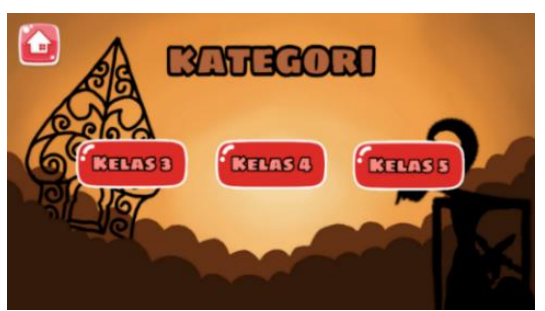

3. Tampilan Permainan

Gambar 6. Tampilan Menu Level

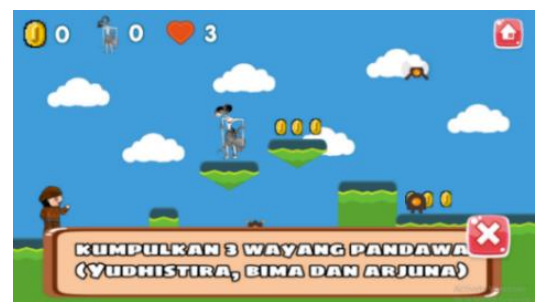

Gambar 7. Tampilan Permainan Kelas 3

4. Tampilan Total Score

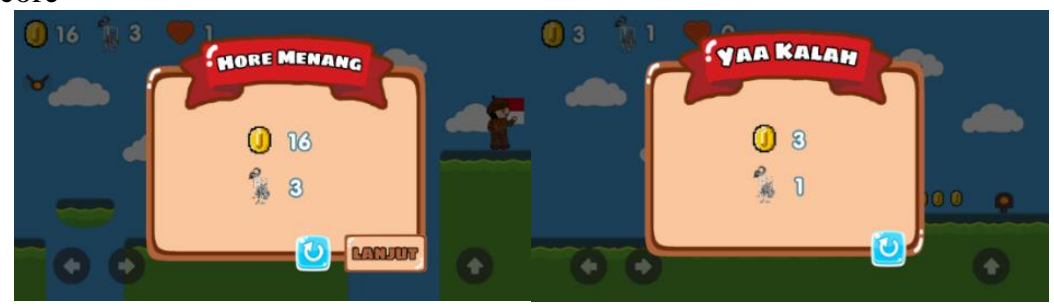

Gambar 8. Tampilan Score Menang dan Kalah

5. Tampilan Informasi Materi Wayang

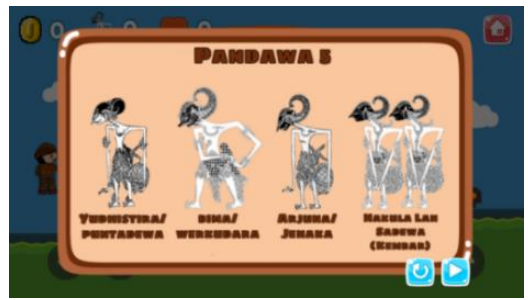

Gambar 9. Tampilan Informasi Wayang Kelas 3 
Procedia of Engineering and Life Science Vol. 1. No. 2 Juni 2021

Seminar Nasional \& Call Paper Fakultas Sains dan Teknologi (SENASAINS 2nd)

Universitas Muhammadiyah Sidoarjo

\section{A. Pengujian aplikasi}

Unit testing

Pada pengujian unit testing ini menggunakan metode whitebox untuk mengetahui aspek uji fungsionalitas terkait dengan software setiap unit.

Tabel 1. Hasil Pengujian Whitebox

\begin{tabular}{cllll}
\hline No. & Nama & Hasil Yang Diharapkan & Hasil Yang Didapatkan & Ketercapaian \\
\hline 1 & Test 1 & $\begin{array}{l}\text { Menampilkan fitur di } \\
\text { menu bantuan dengan } \\
\text { sempurna }\end{array}$ & $\begin{array}{l}\text { Menampilkan fitur di } \\
\text { menu bantuan dengan baik }\end{array}$ & Tercapai \\
\hline 2 & Test 2 & $\begin{array}{l}\text { Menampilkan fitur pilih } \\
\text { kategori kelas dengan } \\
\text { sempurna }\end{array}$ & $\begin{array}{l}\text { Menampilkan fitur pilih } \\
\text { kategori kelas dengan baik }\end{array}$ & Tercapai \\
\hline 3 & Test 3 & $\begin{array}{l}\text { Menampilkan fitur } \\
\text { permainan tiap level } \\
\text { dengan kondisi lulus }\end{array}$ & $\begin{array}{l}\text { Menampilkan dengan baik } \\
\text { fitur permainan tiap level } \\
\text { dengan kondisi lulus }\end{array}$ & Tercapai \\
\hline 4 & Test 4 & $\begin{array}{l}\text { Menampilkan fitur } \\
\text { permainan tiap level } \\
\text { dengan kondisi tidak } \\
\text { lulus }\end{array}$ & $\begin{array}{l}\text { Menampilkan dengan baik } \\
\text { fitur permainan tiap level } \\
\text { dengan kondisi tidak lulus }\end{array}$ & Tercapai \\
& & $\begin{array}{l}\text { Menampilkan fitur } \\
\text { perhitungan score } \\
\text { dengan sempurna }\end{array}$ & $\begin{array}{l}\text { Menampilkan dengan baik } \\
\text { fitur perhitungan score } \\
\text { dengan sempurna }\end{array}$ & Tercapai \\
\hline 5 & Test 5 & $\begin{array}{l}\text { Menampilkan dengan baik } \\
\text { fitur informasi wayang } \\
\text { dengan sempurna }\end{array}$ & Tercapai \\
\hline 6 & Test 6 & $\begin{array}{l}\text { Menampilkan fitur } \\
\text { informasi wayang } \\
\text { dengan sempurna }\end{array}$ & & \\
\hline
\end{tabular}

$$
\text { Tercapai }=\frac{6}{6} \times 100 \%=100 \% \quad \text { dan } \quad \text { Gagal }=\frac{0}{6} \times 100 \%=0 \%
$$

Maka hasil yang didapatkan dari pengujian whitebox terkait dengan unit testing adalah sangat baik.

Integration testing

Pada pengujian integration testing ini merupakan pengujian lanjutan dari pengujian unit testing dan pengujian ini menggunakan metode blackbox testing. Pada pengujian integration ini ditekankan pada uji fungsionalitasnya serta aspek keberhasilan ketika aplikasi dimainkan.

Tabel 2. Hasil Pengujian Blackbox

\begin{tabular}{|c|c|c|c|c|c|}
\hline No. & $\begin{array}{c}\text { Nama } \\
\text { Pengujian }\end{array}$ & Tujuan & Skenario & $\begin{array}{l}\text { Hasil Yang } \\
\text { Diharapkan }\end{array}$ & Ketercapaian \\
\hline 1 & $\begin{array}{l}\text { Running } \\
\text { Aplikasi }\end{array}$ & $\begin{array}{c}\text { Menemukan kendala } \\
\text { yang menyebabkan } \\
\text { error }\end{array}$ & $\begin{array}{l}\text { Menjalankan } \\
\text { aplikasi }\end{array}$ & $\begin{array}{c}\text { Aplikasi } \\
\text { berjalan baik } \\
\text { tanpa error }\end{array}$ & Tercapai \\
\hline 2 & $\begin{array}{c}\text { Menampilkan } \\
\text { Petunjuk } \\
\text { Permainan }\end{array}$ & $\begin{array}{c}\text { Agar user memahami } \\
\text { bagaimana cara bemain }\end{array}$ & $\begin{array}{c}\text { Menekan } \\
\text { tombol di menu } \\
\text { bantuan }\end{array}$ & $\begin{array}{c}\text { Menampilkan } \\
\text { detail } \\
\text { petunjuk } \\
\text { permainan }\end{array}$ & Tercapai \\
\hline 3 & $\begin{array}{l}\text { Memilih } \\
\text { Kategori } \\
\text { Kelas }\end{array}$ & $\begin{array}{l}\text { Melihat apakah fitur } \\
\text { button berjalan dengan } \\
\text { baik }\end{array}$ & $\begin{array}{c}\text { Memilih } \\
\text { kategori } \\
\text { tingkatan kelas }\end{array}$ & $\begin{array}{c}\text { Mampu } \\
\text { menjalankan } \\
\text { fungsionalitas } \\
\text { dan menuju ke } \\
\text { layout yang } \\
\text { sesuai } \\
\end{array}$ & Tercapai \\
\hline 4 & $\begin{array}{l}\text { Memulai } \\
\text { Permainan }\end{array}$ & $\begin{array}{l}\text { Agar pemain dapat } \\
\text { memulai permainan }\end{array}$ & $\begin{array}{l}\text { Memilih level } \\
\text { kelas }\end{array}$ & $\begin{array}{c}\text { Beralih ke } \\
\text { layout } \\
\text { permainan } \\
\text { yang dipilih } \\
\end{array}$ & Tercapai \\
\hline 5 & Score & $\begin{array}{l}\text { Melihat dan juga } \\
\text { memperbaiki jika } \\
\text { terdapat bugs dalam } \\
\text { score }\end{array}$ & $\begin{array}{c}\text { Menjalankan } \\
\text { permainan serta } \\
\text { mengamati } \\
\text { perubahan } \\
\text { dalam score }\end{array}$ & $\begin{array}{l}\text { Sistem score } \\
\text { dapat berjalan } \\
\text { dengan baik }\end{array}$ & Tercapai \\
\hline
\end{tabular}




\begin{tabular}{|c|c|c|c|c|c|}
\hline 6 & $\begin{array}{l}\text { Info Materi } \\
\text { Wayang }\end{array}$ & $\begin{array}{c}\text { Menampilkan } \\
\text { informasi wayang }\end{array}$ & $\begin{array}{l}\text { Menyelesaikan } \\
\text { permainan } \\
\text { kemudian } \\
\text { mendapatkan } \\
\text { PopUp info } \\
\text { wayang }\end{array}$ & $\begin{array}{l}\text { Menampilkan } \\
\text { PopUp info } \\
\text { materi } \\
\text { wayang } \\
\text { dengan baik }\end{array}$ & Tercapai \\
\hline
\end{tabular}

$$
\text { Tercapai }=\frac{6}{6} \times 100 \%=100 \% \quad \text { dan } \quad \text { Gagal }=\frac{0}{6} \times 100 \%=0 \%
$$

Maka hasil yang didapatkan dari pengujian blackbox terkait dengan unit testing adalah sangat baik.

\section{System testing}

Pada tahap system testing atau percobaan sistem ini, pengujian dilakukan dengan menggunakan metode stress testing dalam pengujian Stability, Reliability, dan pengujian Compatibility.

1. Install dan Launch System Testing

Pada tahap pengujian Reability dan Compabilty ini dilakukan dengan cara memasang serta menjalankan aplikasi pada beberapa sistem operasi dengan perangkat dan juga ukuran layar yang berbeda yaitu pada Android Marsmelow 6.0 (1080 x 1920) dan Android Pie 9.0 (1080 x 2220). Dari hasil pengujian yang telah dilakukan di 2 sistem operasi yang memiliki resolusi dan juga versi android yang berbeda, game pengenalan tokoh wayang ini dapat diaplikasikan dengan baik. Dengan presentase ketercapaian mencapai $100 \%$.

2. Stress Testing

Pada tahap pengujian stress testing ini dilakukan untuk mengetahui apakah ada bugs dan penurunan performa apabila digunakan secara acak di Asus Zenfone Selfie, Samsung A10 dan Samsung A7 2018. Dan dari hasil pengujian tersebut dapat disumpulkan bahwa tidak ada bugs dan juga penurunan performa sehingga persentase yang diperoleh mencapai $100 \%$.

3. Acceptance Testing

Pada tahap pengujian Acceptance Testing ini dilibatkan end-user agarap dapat memasyikan apakah aplikasi game pengenalan tokoh wayang ini dapat diterima serta sudah layak untuk digunakan atau belum.

a. Hasil Pengujian Kepada Siswa

Tahap ini mamakai kuisioner sebagai metode pengujiannya serta akan dibagikan kepada 9 siswa kelas 3-5 secara acak serta ada 7 pertanyaan yang diajukan dan menggunakan skala 1-3 dengan skor maksimal yaitu 189 dan total skor yang didapat yaitu 184. Digunakan juga analisis Likert untuk merubah data yang ada pada tabel pengujian diatas menjadi data kualitatif. Sehingga rata-rata yang didapatkan sebagai berikut :

$$
\text { Rata }- \text { Rata }=\frac{\text { Jumlah Nilai }}{\text { Banyak Nilai }} \times 100 \%=\frac{184}{189} \quad \times 100 \%=97 \%
$$

b. Hasil Pengujian Ahli Materi

Pengujian dari ahli materi terdapat 7 pertanyaan yang diajukan dan menggunakan skala 1-3 dengan skor maksimal yaitu 21 poin. Hasil yang diperoleh dari pengujian yaitu mencapai 21 poin dengan presentase $100 \%$.

$$
\text { Rata }- \text { Rata }=\frac{\text { Jumlah Nilai }}{\text { Banyak Nilai }} \times 100 \%=\frac{21}{21} \quad \times 100 \%=100 \%
$$

c. Hasil Pengujian Ahli Media

Pengujian dari ahli materi terdapat 8 pertanyaan yang diajukan dan menggunakan skala 1-3 dengan skor maksimal yaitu 24 poin. Hasil yang diperoleh dari pengujian yaitu mencapai 18 poin dengan presentase $75 \%$.

$$
\text { Rata }- \text { Rata }=\frac{\text { Jumlah Nilai }}{\text { Banyak Nilai }} \times 100 \%=\frac{18}{24} \quad \times 100 \%=75 \%
$$

Kesimpulan yang diperoleh menurut tabel diatas bahwa hasil uji Playability dari game pengenalan tokoh wayang ini mendapatkan presentasi sebesar $91 \%$ dan dapat dikategorikan sangat baik. Hasil dari ketercapaian dapat diketahui melalui pengujian yang telah dilakukan sebelumnya dan didapat kesimpulan sebagai berikut : Pengujian Functionality (Unit \& Integration Testing), Reability, Compability presentase ketiga pengujian mencapai $100 \%$ dan pengujian Playability mencapai $91 \%$. Sehingga dapat disimpulkan bahwa kelayakan game pengenala tokoh wayang ini jika dilihat dari 4 aspek pengujian tersebut memiliki kategori sangat layak dengan rata-rata presentase sebesar $98 \%$. 


\section{KESIMPULAN}

Dalam penelitian yang telah dilakukan untuk pengembangan Game Pengenalan Tokoh Wayang Berbasis 2D ini, maka dapat dibuat kesimpulan yaitu, dapat menambah pengetahuan dan ketertarikan siswa dalam belajar mengenai wayang dengan diberikan efek suara nama wayang pada object wayang sehingga efektif digunakan untuk menarik minat siswa dalam memahami materi pewayangan yang ada dalam mata pelajaran Bahasa Jawa. Dilakukan juga pengujian untuk melihat penilaian dari permainan yang sudah dibuat ini, didapatkan nilai aspek dari pengujian functionality, reability, compability yang mencapai $100 \%$, dan juga pengujian playability yang mendapatkan respon sangat baik dengan persentase mencapai 98\%. Sehingga dikategorikan layak untuk dapat dimainkan. Peniliti memiliki saran dan juga pandangan bagaimana pengembangan Game Pengenalan Tokoh Wayang Berbasis 2D ini untuk penelitian selanjutnya antara lain : Menambahkan animasi, effects dan juga behavior yang lebih menarik lagi pada gameplay serta dapat melakukan pengembangan game pada beberapa platform game dan pada sistem operasi yang berbeda juga seperti iOS ataupun juga PC desktop.

\section{UCAPAN TERIMA KASIH}

1. Dr. Hidayatullah, M.Si, selaku Rektor Universitas Muhammadiyah Sidoarjo yang telah menyediakan fasilitas pada kegiatan perkuliahan.

2. Dr. Hindarto, S.Kom., M.T., selaku Dekan Fakultas Sains dan Teknologi yang telah menyediakan fasilitas pada kegiatan perkuliahan.

3. Ir. Sumarno, MM., selaku Kaprodi Informatika yang telah menyediakan fasilitas dalam kegiatan perkuliahan.

\section{REFERENSI}

[1] Anggoro, Bayu. (2018). Wayang dan Seni Pertunjukan: Kajian Sejarah Perkembangan Seni Wayang di Tanah Jawa sebagai Seni Pertunjukan dan Dakwah. JUSPI : Jurnal Sejarah Peradaban Islam. Vol.2, No.2.

[2] Ariyana, R.Y., dkk. (2020). Pengembangan Puzzle Game Wayang Punakawan Sebagai Media Pengenalan Seni dan Budaya Pada Anak. Jurnal Teknologi: Vol. 13, No. 1.

[3] Baskoro, R.Y. (2014). Pembuatan Game “Jumping Galaxy” Menggunakan Game Engine Construct 2. Yogyakarta: Naskah Publikasi.

[4] Jasson. (2009). Role Playing Game (RPG) Maker. Yogyakarta: Penerbit Andi.

[5] Nahak, dkk (2019). Upaya Melestarikan Budaya Indonesia Di Era Globalisasi. Jurnal Sosiologi Nusantara : Vol.5, No.1.

[6] Nurlaili, A.F., dkk. (2016). Pengembangan Multimedia Untuk Pengenalan Tokoh Wayang Dalam Pembelajaran Bahasa Jawa. Jurnal Pendidikan : Teori, Penelitian, dan Pengembangan. Vol. 1, No. 7. Halaman : 1427-1431. EISSN : 2501-471X.

[7] Rahman, R.A., dkk. (2016). Pengembangan Game Edukasi Pengenalan Nama Hewan Dan Habitatnya Dalam A3 Bahasa Sebagai Media Pembelajaran Berbasis Multimedia. Jurnal Algoritma Sekolah Tinggi Teknologi Garut. ISSN : 2302-7339 Vol.13 No.1.

[8] Sukamto, R.A., dkk. (2011). Modul Pembelejaran Rekayasa Perangkat Lunak : Terstruktur dan Berorientasi Objek. Bandung : Modula. ISBN : 978-602-8759-13-7

[9] Sukirno. (2009). Hubungan Wayang Kulit Dan Kehidupan Sosial Masyarakat Jawa. Jurnal Kajian Teori, Praktik dan Wacana Seni Budaya Rupa. Vol. 1, No. 1.

[10] Tholani, M.I. (2013). Problematika Pendidikan di Indonesia (Telaah Aspek Budaya). Jurnal Pendidikan: Vol. 1, No. 2. ISSN: 2337-7607. 